\title{
Kenya update: FRONTIERS adolescent reproductive health project
}

Frontiers in Reproductive Health

Follow this and additional works at: https://knowledgecommons.popcouncil.org/departments_sbsr-rh

Part of the Demography, Population, and Ecology Commons, Health Services Research Commons, and the International Public Health Commons How does access to this work benefit you? Let us know!

\section{Recommended Citation}

"Kenya update: FRONTIERS adolescent reproductive health project," FRONTIERS Project Update. Nairobi: Population Council, 2001. 


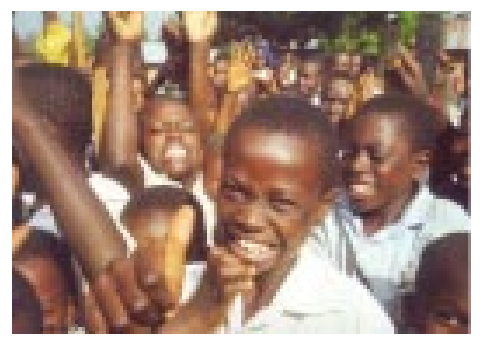

July 2001

Issue No. 1
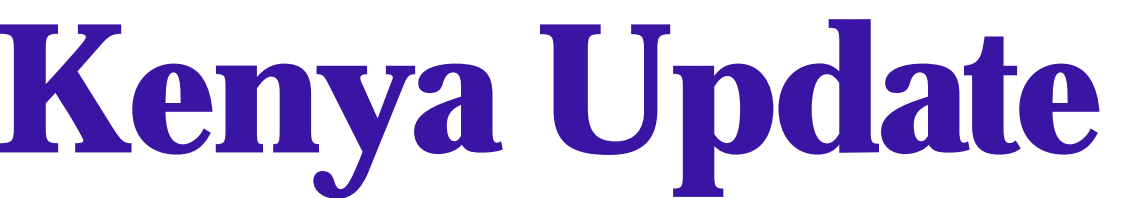

The Kenya Adolescent Reproductive Health Project (KARHP) was launched in October 1999 in Busia and Vihiga districts as a threeyear operations research study to determine the feasibility, cost and effectiveness of implementing systematic interventions that address the Reproductive Health (RH) needs of adolescents aged 10-19 years. This USAID-funded project is part of the Population Council's Frontiers in Reproductive Health Program global operations research programs. PATH (Program for Appropriate Technology in Health) is implementing the project, in collaboration with the Ministries of Health, Education, and Home Affairs, Heritage and Sports.

The objective of the study is to establish the effectiveness of interventions designed to increase adolescents' RH knowledge, delay the onset of sexual activity, increase adolescent use of RH services and reduce risky sexual behaviour.

The project has three sites, two intervention and one control. In Site A, two approaches are being implemented - a community based one to improve the social environment and foster positive attitudes to meeting the RH needs of youth and a health facility based one to improve youth friendliness of services. Site A is being implemented in West Maragoli and Marachi East locations in Vihiga and Busia districts respectively. The second intervention site (Site B) includes these two approaches plus school-based RH information and referral services, and is being implemented in Wodanga and Nambale township locations in Vihiga and Busia district. Izava and Central Marachi locations in Vihiga and Busia districts respectively, are the control sites (Site C) where no new approaches have been introduced.

\section{Community-based Interventions}

The community-based intervention comprises two components. The first is geared towards sensitising stakeholders in the community about the need for adolescent RH services and information. To do this, KARHP staff holds oneto-one and small group meetings with community leaders and convenes dissemination meetings.

The project has trained two theatre groups that stage performances on $\mathrm{RH}$ topics at project workshops and community gatherings. In September 2000, these theatre groups disseminated baseline survey and diagnostic study findings at the community level. The project used this dissemination workshop to improve community members understanding of the adolescent reproductive health situation, to engage their participation in the design of the interventions and to secure their support for project activities. 
The second component involves providing services and information to adolescents through out-of-school peer educators, who were selected and trained by service providers from the public sector in October and November 2000. The training curriculum for peer educators comprises the following eight modules:

- Human anatomy and physiology, puberty and maturation

- Relationships, including romantic relationships

- Values clarification, including self efficacy, aspirations and negotiation skills

- Sexual behaviour, including intimacy, forms of sexual expression and sexual satisfaction.

- Gender issues, including sexual violence (rape, molestation, defilement, and any form of sex abuse) and how to prevent it, and gender discrimination or differences

- Negative consequences and risks of sexual behaviour, including loss of relationship and reputation, guilt, family disapproval, unintended pregnancy and STIs

- Motivation for sexual behaviour, including desiring pregnancy, desiring intimacy, and maintaining relationships.

- Protective behaviour, including condom use, having one mutually faithful partner and abstinence.

The out-of-school peer educators disseminate $\mathrm{RH}$ information to groups of youth through a variety of methods including drama, songs, poems, video shows and debates. They use several avenues to reach youth, such as religious meetings and youth groups and clubs. They also provide one-to-one information, counselling, and referral services to individual youths. In addition, they distribute condoms to the youth and demonstrate use.

In January 2001, project personnel trained four Social Development Assistants (SDA) from the Ministry of Home Affairs, Heritage and Sports to provide support to and coordinate the activities of community-based peer educators. SDAs organise activities to educate various groups at the community level. They develop work plans to guide the implementation of community-based activities and assist peer educators in developing their own activities. They also report on all activities carried out in their areas.

Between January and March, several outreach events were carried out in all the four intervention sites to launch the project and to sensitise the communities about its activities and the importance of providing $\mathrm{RH}$ information and services to adolescents. Intervention schools' teachers and students, peer educators, health providers, parents, religious and elected leaders and representatives of NGOs working in the area participated in these activities which were also covered by the local press (The Daily Nation and The East African Standard) and the national radio station (Kenya Broadcasting Corporation). Leaders and parents were encouraged to discuss the problems facing the youth and to urge them to seek RH services and information.

Out-of-school youth were targeted through the entertainment activities, which focussed on songs, drama, poems, and narratives. Service providers presented short health talks to complement the messages delivered through the public performances. Through the outreach ctivities, a total of 5,225 adolescents and 748 parents were reached with reproductive health information.

\section{Number reached through outreach campaigns in March 2001}

\begin{tabular}{|l|c|c|c|c|c|}
\hline \multirow{2}{*}{ Site } & \multicolumn{2}{|c|}{ Adolescents } & \multicolumn{2}{c|}{ Parents } & \multirow{2}{*}{ Total } \\
\cline { 2 - 5 } & Male & Female & Male & Female & \\
\hline Wodanga & 1205 & 1837 & 94 & 74 & 3,210 \\
\hline Nambale & 794 & 659 & 112 & 66 & 1,631 \\
\hline Marachi East & 258 & 101 & 147 & 58 & 564 \\
\hline West Maragoli & 196 & 175 & 62 & 135 & 568 \\
\hline Total & 2453 & 2772 & 415 & 333 & 5973 \\
\hline
\end{tabular}


To increase religious leaders' understanding of objectives of the project and facilitate their participation in the project activities, in May 2001 , project personnel trained 44 religious leaders representing the various Christian and Islamic groups in the intervention sites. In addition to expressing support for project activities, each religious group developed plans and presentations indicating how they would integrate adolescent sexual and $\mathrm{RH}$ into their existing religious activities.

Religious leaders from each intervention site developed specific work plans indicating venues and dates when they would conduct joint adolescent sexual and RH activities targeting both parents and adolescents. Two such activities were implemented on 16th and 30th June 2001 in West Maragoli location reaching 79 parents and 224 youths.

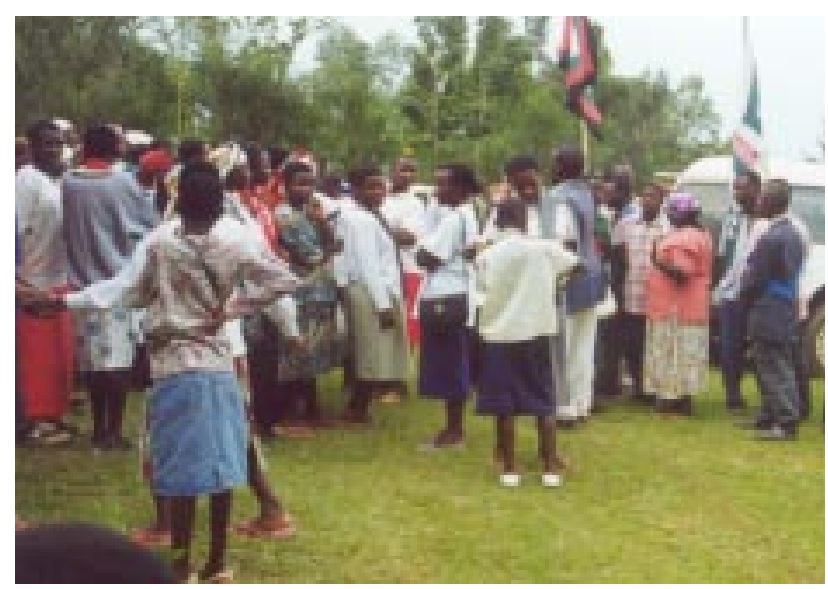

Participants at an outreach meeting organised by religious leaders at Kivagala PAG Church, West Maragoli

"For a long time development agencies have sidelined religious leaders from their intervention strategies for fear that they will get opposition from us ... but other organizations need to learn from PATH that if properly sensitized, the religious leaders can be on the frontline of community mobilization .... After all, we have a captive audience every week.

Religious leader during an interdenominational KARHP activity at Kivagala PAG Church, West Maragoli location

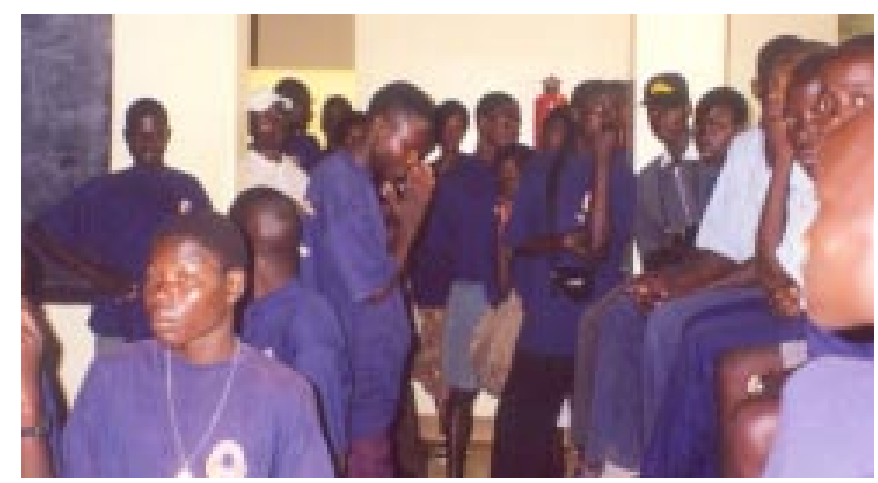

Community-based peer educators during an activity at the health centre

\section{Health facility-based intervention}

The health facility-based intervention is designed to establish whether making services more youth-friendly will increase the use of existing $\mathrm{RH}$ services by adolescents. To date, the project has trained a team of 37 health facility staff from four public health centres and 14 dispensaries and private clinics to provide quality and youth friendly services. The training is designed to change the attitudes of the staff towards providing services to youth and to equip them with skills to improve the quality of adolescent services. Support and paramedical staffs were oriented in providing adolescent friendly services, in order to improve the total health facility environment.

Each intervention site has a Ministry of Health $(\mathrm{MOH})$ health centre. In each of the four health centres, the project has set aside a room for youth. These rooms have been repainted and supplied with Information Education and Communication (IEC) materials and basic furniture. Youth are free to come to this room to read materials and receive counselling. All the 18 public and private participating health facilities have signposts, which indicate the services available. Most of the clinics are open Monday to Saturday between 8.00 a.m. and 5.00 p.m. The service providers have helped to put in place a system that records all young people aged 10-19 who receive services at the health facilities.

\section{School-based interventions}

Twenty-two schools (17 primary and five secondary) from Nambale Township and Wodanga locations in Busia and Vihiga Districts respectively, are involved in the study. Through the school-based intervention, the project is testing whether 
providing $\mathrm{RH}$ information in schools will make a significant contribution to the $\mathrm{RH}$ knowledge and behaviour of adolescents and their use of RH services.

Seventy-nine guidance and counselling teachers are involved. After their training in August 2000, they discussed the project and its intended activities with their colleagues and the student community, in order to remove misinformation and gain their support. Given the controversies in Kenya regarding sexuality education in schools, it was important that the school community understand that KARHP was not about sex but reproductive health education. The teachers use the Parents Teachers Association (PTA) and the school Board of Governors (BoG) to sensitise parents on the objectives of the project and the need to address RH problems facing adolescents.

The teachers implement the project's 34-hour in-school curriculum. In most schools, the sessions are held after school hours in individual or combined classes. In others, club and lesson times for other nonexaminable subjects such as physical education are currently devoted to the project activities.

The school-based intervention also uses peer educators who were recruited and trained by the

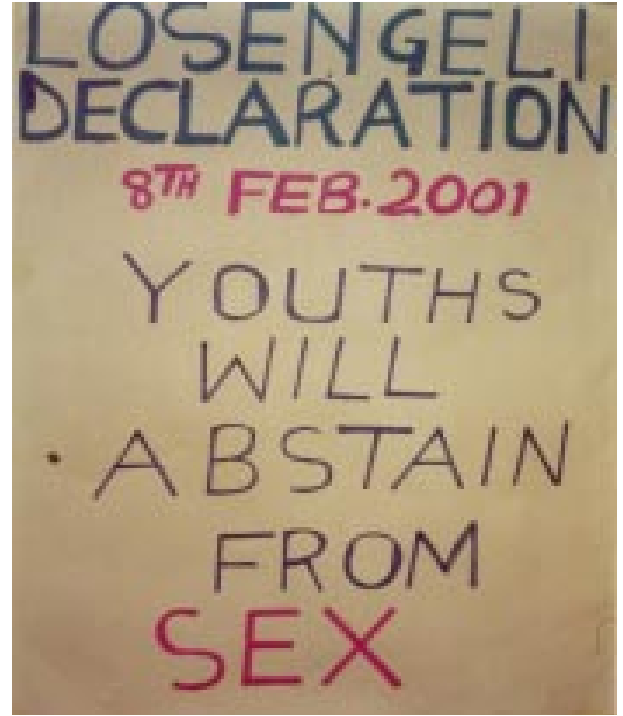

A declaration by one secondary school posted on the school notice board

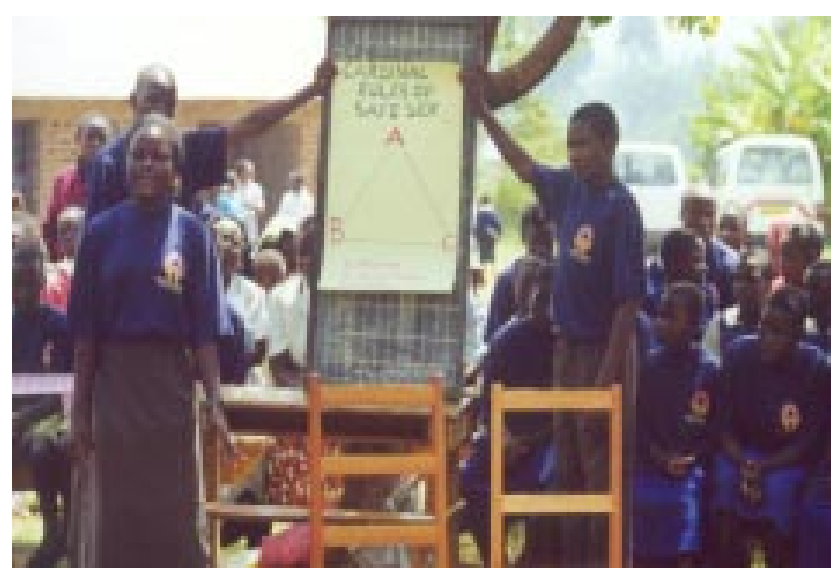

Peer educators at a school meeting

the Assistant Education Officer to plan together and share experiences. These meetings have been very useful in encouraging schools that have been slow in implementing the intervention. The meetings also encourage schools to try new ways of intensifying their education and outreach.

Refresher training and continuous education is planned to help build teachers and peer educators' capacity to respond to the project's challenges. Future training will be in one-day sessions following a thematic approach. For example, gender violence has been the theme for the months of April, May and June. For each theme, appropriate materials are provided to assist in information sharing and discussion. teachers. The peer educators educate other students through group meetings and individually. With the assistance of the teachers, the peer educators compose songs, poems, and skits for use during group education sessions. They also make referrals to guidance and counselling teachers and youth-friendly service providers. The teachers help to organise school debates on various reproductive health topics.

Each school has set aside a Guidance and Counselling room where the trained teachers meet with students needing assistance. Teachers refer difficult cases to trained service providers. Every two months, the teachers in all the schools per site meet with
"Today I want to confess to all the school heads attending this important workshop that I have undergone a major transformation on the impression I had about KARHP. When I first heard about KARHP, my impression fast drifted into condoms and sex. Nevertheless, through the workshop, I have learnt a lot of real problems that affect young people and require practical solutions. I believe that through KARHP, our young people, parents, religious leaders, teachers and the communities will have hope for tomorrow .... I am going to mobilize young people within our parish in liaison with the Father-in-Charge of the parish so that they can benefit from these talks and watch these videos. This project should be extended to cover others. I think the pilot phase is already over ... let us get into business". (A Catholic nun who is head teacher, Kisoko Girls Primary School, Busia.) 


\section{Information Education and Communication (IEC)}

In addition to the training curricula and guides for developing skits, the project has designed and adopted various adolescent sexual and reproductive health IEC materials. Each school has received a supply of the Safari Game Board developed by PATH to facilitate RH discussion and provide facts. Each project staff and peer educator has received a T-shirt with an imprint of the Project logo and the message "I am a peer educator. Ask me about adolescent health".

The following videos have been distributed for use in the 4 sites - More time; Yellow card; Silent epidemic; The lesser child; It is not easy; Siyo rahisi; Consequences; Facing the challenge; The brave response; Raised voices; and The voices of young mothers. In addition, the project has distributed posters (A Moment of Passion, a Lifetime of Regret and Don't Gamble With Your Life - Use Condoms) and many leaflets, brochures and fact sheets.

\section{Management Information Systems (MIS)}

Project service providers, teachers, and peer educators keep records of their monthly activities. Health providers keep monthly records of:

- Number of adolescents visiting the health facility by age, sex and type of service

- Number of adolescents referred by teachers and peer educators

- Number of condoms distributed to peer educators

- Number of community and schoolbased outreach activities

Teachers keep monthly records of:

- Number of adolescents receiving individual counselling

- Number of adolescents referred to health facility

- Number of curriculum sessions covered

- Number of students (by sex and class) exposed to the various sessions covered
Both school and community-based peer educators keep monthly records of the following:

- Number of individuals reached with information by sex and topic

- Number of youth referred to health facility (or teacher for school-based)

- Number of group contacts

- Number of people reached through group contact and topics covered

- Number of condoms distributed to youth (out-of-school youth)

- Number and type of IEC materials distributed

To facilitate calculation of costs, all project implementers fill in their monthly activity forms the time taken to plan and execute the activities.

\section{Supervision}

To strengthen activity monitoring and supervision, the project developed monthly reporting schedules for use by peer educators, service providers and teachers, in which they indicate their activities. The field supervisors and the project field coordinator visit the facilities every month to ensure that records are properly maintained. A database has been set up to capture service data. In February 2001, nine school inspectors were trained to supervise the implementation of the school-based intervention, while four clinical officers and four SDAs were trained to supervise health facility-based and community-based activities respectively. All the supervisors have developed supervision checklists.

\section{Constraints}

Due to marriage, employment, training and business opportunities outside the intervention sites, as well as lack of motivation, the project has lost over twenty community-based peer educators. Secondly, the Ministry of Education's decision early this year to shorten the number of hours per primary school day means that the peer educators and schoolteachers have only 30 minutes per day to carry out project activities.

This has made the implementation of the curriculum difficult. 
The project has also experienced limitations in access to video facilities. At present, the project has only one TV/video player set, which has to be shared among the four intervention locations. Although the videotapes have proved to be a good way of mobilising and educating young people, and supporting the peer educators' activities, the lack of equipment is hampering their use.

Accurate record keeping remains a challenge to the project. While the field personnel have been trained to use the cost and activity monitoring forms for the project, many have difficulties completing the forms correctly, while others do not submit them at all. Part of the problem may have been that the project had too many forms, therefore causing confusion and work overload. As a result of the revision of monitoring forms coupled with further training in completing them, peer educators have shown some improvement in record keeping.

Most health facilities have client record keeping formats that do not require client age to be registered. The project has encouraged intervention site providers to include a column for age in the $\mathrm{MOH}$ recordkeeping formats and supplied record-keeping books in facilities that do not have them. However, keeping proper records in the control site health facilities has remained a challenge to the project as not all staff remember to consistently record age.

Finally, the question of compensation for the out-of-school peer educators has been raised repeatedly. Most complain that they use their own money to attend meetings and participate in other group activities and have requested transport and work allowances. Although this was not budgeted in the project, the Project Implementation Team is working to ensure that, at a minimum, the peer educators are reimbursed for transportation costs.

\section{Lessons Learned}

The success of KARHP to date has demonstrated that it is feasible to implement a broad-based adolescent reproductive health project both at the community and school levels. However, this requires a systematic and thorough sensitisation program for various community stakeholders and their involvement in designing and implementing project activities.

Religious leaders are suspicious of the motives of non-religious projects that address adolescents reproductive health needs. However, exposing religious leaders to the objectives of the project and providing them with a forum to debate and discuss adolescents reproductive health issues among themselves reduces their suspicion and increases their willingness to address reproductive health needs of adolescents in their communities. Relying on communitybased peer educators who are not provided with monetary incentives has been a weakness of the community education component.

For more information, contact

\author{
Samson Radeny \\ PATH Regional Office \\ ACS Plaza, \\ Lenana Rd. \\ Tel.: (254-2) 577177, Fax: (254-2) 577172 \\ P O Box 76634 \\ Nairobi
}

\author{
Dr. Jane Chege \\ Population Council \\ FRONTIERS in Reproductive Health \\ General Accident Insurance House, \\ Ralph Bunche Rd. \\ Tel. (254-2) 713480, Fax: (254-2) 713479 \\ P O Box 17643 \\ Nairobi
}

